\title{
PENINGKATAN KOMPETENSI PEDAGOGIK GURU MELALUI SUPERVISI AKADEMIK DI SMP NEGERI 4 PONTIANAK
}

\author{
Neti Herwati \\ SMP Negeri 4 Pontianak \\ Email : netiherwati@65id.com
}

\begin{abstract}
This research is aimed to improve the pedagogical competence of teachers at SMP Negeri 4 Pontianak. This research was conducted in two cycles, in each cycle having planning, implementation, observation and reflection. Data analysis techniques that guide data management by using a percentage (\%) to achieve a constant of 100. A maximum score of 92 out of seven pedagogical competencies consisting of; Competency 1; Get to know the characteristics of students. Competency 2; Mastering learning theory and principles of learning. Competency 3; Curriculum Development. Competency 4: Educating learning activities. Competency 5; Understand and develop potential. Competency 6; Communication with students. Competency 7: Assessment and evaluation. Research Results in the first cycle the lowest value of $70 \%$ and in the second cycle the lowest value of $80 \%$. The highest average value in cycle I was $79 \%$ and the highest average value in cycle II was $84 \%$. There is an increase in percentage of teacher pedagogical competence through academic supervision by $5 \%$ from cycle I.
\end{abstract}

Keywords: Improvement, Pedagogical Competence, Teacher, Academic Supervision

\section{PENDAHULUAN}

Dalam upaya mengembangkan kompetensi yang dimiliki kepala sekolah dapat mengacu pada Peraturan Menteri Pendidikan Nasional (Permendiknas) No.13 Tahun 2007 tentang Standar Kepala Sekolah memberikan acuan bagi pengembangan kompetensi Kepala Sekolah, yang terdiri dari lima dimensi kompetensi, yaitu: (1) kepribadian; (2) managerial; (3) kewirausahaan;(4) supervisi; dan (5) sosial. Untuk itu diperlukan upaya terus menerus untuk mengembangkan kompetensi para Kepala Sekolah, agar dapat memenuhi kompetensi yang diharapkan.

Tugas pokok kepala sekolah dalam usaha mengembangkan sekolah, yaitu bagaimana upaya kepala sekolah dalam ;(1) menyusun atau menyempurnakan visi,misi dan tujuan sekolah; (2) menyusun struktur organisasi sekolah; (3) menyusun rencana kerja jangka panjang (RKJM) dan rencana kerja tahunan (RKT) ; (4) menyusun peraturan sekolah; (5) mengembangkan sistem informasi.

Kepala Sekolah mempunyai tugas yang sangat penting di dalam mendorong guru untuk melakukan proses pembelajaran untuk mampu menumbuhkan kemampuan kreatifitas, daya inovatif, kemampuan pemecahan masalah, berpikir kritis dan memiliki naluri jiwa kewirausahaan bagi siswa sebagai produk suatu sistem pendidikan. Disamping itu seorang Kepala Sekolah diharapkan menguasai dan mempunyai 6 aspek yang akan dinilai kinerjanya, yaitu: (1) kepribadian dan sosial; (2) kepemimpinan pembelajaran; (3) pengembangan sekolah; (4) manajemen sumber daya; (5) kewirausahaan; (6) dan supervisi pembelajaran.

Sebagai pemimpin pembelajaran Kepala Sekolah memiliki peran yang kuat dalam mengkoordinasikan, menggerakkan, dan menyerasikan semua sumberdaya pendidikan yang tersedia. Kepemimpinan Kepala Sekolah merupakan salah satu faktor yang dapat mendorong sekolah untuk dapat mewujudkan visi, misi, tujuan, dan sasaran sekolahnya melalui program-program yang dilaksanakan secara terencana dan bertahap.

Oleh karena itu, Kepala Sekolah dituntut memiliki kepemimpinan yang tangguh agar mampu mengambil keputusan untuk meningkatkan mutu sekolah. Kepala Sekolah tangguh memiliki 
kemampuan memobilisasi sumber daya sekolah, terutama sumberdaya manusia, dapat meningkatkan disiplin seluruh warga sekolah untuk mencapai tujuan sekolah.

Kepala sekolah sebagai faktor penentu dalam meningkatkan kualitas pendidikan juga dikemukan oleh (Mulyasa, 2007) dikatakan bahwa kepala sekolah adalah penengung jawab atas penyelengaraan pendidikan,administrasi sekolah , pembinaan tenaga pendidik lainnya, pendaya gunaan serta pemeliharaan sara dan prasarana ,juga sebagai supervesor pada sekolahnya. Agar sekolah dapat mencapai tujuannya secara efektif dan efesien.

Instrumen penilaian kinerja guru berdasarkan Peraturan Menteri Pendidikan Nasional Nomor 16 tahun 2017 tentang standar Kualifikasi Akademik dan Kompetensi Guru; (1) BSNP versi 6.0.11 tahun 2008 tentang kerangka indikator untuk pelaporan pencapaian standar pendidikan ; (2) Standar kwalifikasi dan kompetensi guru; (3) Permenneg PAN dan RB nomor 16 tahun 2009 tentang jabatan fungsional dan angka kreditnya.

Berdasar kan Intrumen penilaian kinerja guru dan sasaran kinerja pegawai memiliki empat kompetensi yang harus dimiliki diantaranya : (1) kompetensi pedagogik yang memiliki tujuh indikator ; a) Mengenal karakteristik peserta didik, b) Menguasai teori belajar dan prinsip-prinsip pembelajaran yang mendidik, c) Pengembangan kurikulum, d) kegiatan pembelajaran yang mendidik, e) memahami dan mengembangkan potensi, f) komunikasi dengan peserta didik dan g) penilaian dan evaluasi.

Berdasarkan teori dan fakta yang telah dijelaskan di atas, peneliti tertarik melakukan penelitian tentang peningkatan kompetensi pedagagogik guru melalui supervisi akademik di SMP Negeri 4 Pontianak.

\section{METODE PENELITIAN}

Bentuk penelitian yang digunakan dalam penelitian ini adalah Penelitian Tindakan Sekolah (PTS) yang dapat didefinisikan sebagai penelitian tindakan (actian research) yang dilakukan oleh kepala sekolah yang sekaligus sebagai peneliti di kelas atau bersama-sama dengan guru lain yang di tunjuk sebagai supervisor (kalaborasi) dengan cara merancang, melaksanakan dan merefleksi tindakan secara kolaboratif dan partisipasif yang bertujujan untuk memperbaiki atau meningkatkan mutu (kualitas) proses pembelajaran dikelas melalui tindakan (treatment) tertentu dalam suatu siklus.adalah suatu kegiatan yang dilakukan oleh kepala sekolah atau bersam-sama dengan orang lain (kolaborasi) yang bertujuan memperbaiki atau meningkatkan mutu proses pembelajaran dikelasnya.(Kusnandar, 2008).

Penelitian Tindakan Sekolah (PTS) ini dilaksanakan di SMP Negeri 4 Pontianak dari bulan Juli-Desmber 2019. Subjek penelitian adalah 15 orang guru SMP Negeri Pontianak yang diambil secara acak.

Rancangan tindakan dilakukan dengan prosudur penelitian berdasarkan pada prinsip Kemmis dan taggart (1988) yang mencakup kegiatan sebagai berikut; Penelitian akan dilaksanakan sebanyak 2 (dua) siklus dengan tahapan sebagai berikut:

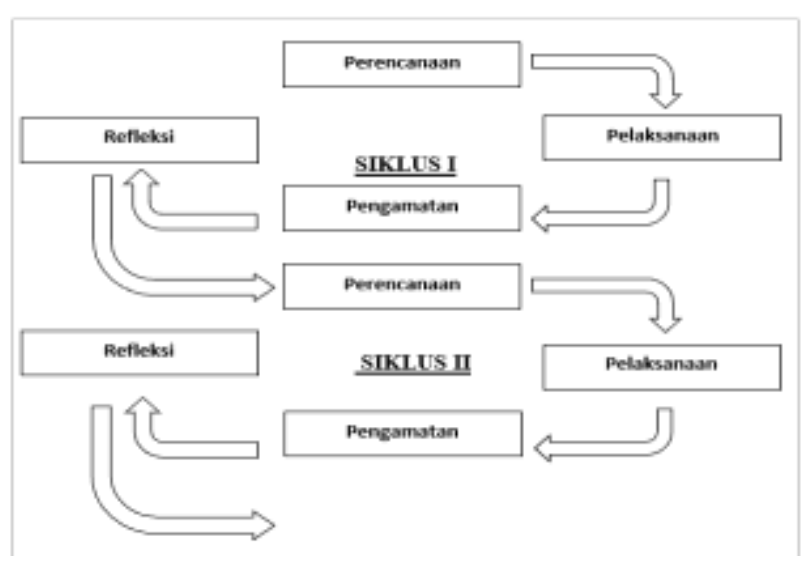

\section{Gambar 1. Siklus Penelitian Tindakan Sekolah}

Teknik pengumpulan data dalam penelitian ini mengunakan Teknik observasi. Observasi adalah kegiatan pengamatan (pengambilan data) untuk melihat seberapa jauh efek tindakan telah mencapai sasaran (Kunandar,2008).

Alat pengumpulan data dalam penelitian ini adalah lembar observasi guru dan dokumentasi. Lembar observasi guru berupa pertanyaan masingmasing setiap indikator dalam bentuk skala likert jika pernyataan tidak ada bukti atau tidak terpenuhi skor 0 , jika pernyataan terpenuhi sebagian skor 1 , jika pernyataan seluruhnya terpenuhi skor 2 . Alat dokumentasi berupa foto, digunakan peneliti untuk 
mendokumentassikan seluruh proses kegiatan guru pada saat supervisi akademik di kelas.

Adapun analisa data yang menjadi pedoman pengelolaan data oleh penulis, mengacu kepada $\mathrm{M}$. Ngalimin Purwanto (1987) dengan rumus sebagai berikut $: \mathbf{P}=\mathbf{R} / \mathbf{T} \times \mathbf{1 0 0 \%}$. Keterangan : $\mathrm{P}=$ Persentase; $\mathrm{R}=$ Jumlah skor yang di peroleh; $\mathrm{T}=$ Jumlah total skor maksimal; $100=$ Konstanta

Data untuk melihat interpertasi dengan mengggunakan criteria interpertasi skor (Arikunto, 2009) untuk memperkuat penafsiran dalam kesimpulan sebagai berikut:

Angka $80 \%-100 \%=$ Baik Sekali

Angka $66 \%-79 \%=$ Baik

Angka $56 \%-65 \%=$ Cukup

Angka $40 \%-55 \%=$ Kurang

\section{HASIL PENELITIAN DAN PEMBAHASAN Hasil Penelitian \\ Siklus 1}

Berikut ini adalah data hasil observasi kompetensi pedagogik guru SMP Negeri 4 Pontianak pada siklus 1 (Tabel 1 dan Tabel 2).

Tabel 1. Rekapitulasi Perolehan Skor Setiap Kompetensi Pedagogik Siklus I

\begin{tabular}{|c|c|c|c|c|c|c|c|c|c|c|c|}
\hline \multirow{2}{*}{ No } & \multirow{2}{*}{$\begin{array}{l}\text { Nama } \\
\text { Guru } \\
\text { (kode) }\end{array}$} & \multirow{2}{*}{ Mapel } & \multicolumn{7}{|c|}{ Rata-Rata Perolehan Skor } & \multirow{2}{*}{ Jumlah } & \multirow{2}{*}{$\begin{array}{c}\text { Persentase } \\
(100 \%)\end{array}$} \\
\hline & & & 1 & 2 & 3 & 4 & 5 & 6 & 7 & & \\
\hline 1 & DB & MTK & 10 & 10 & 7 & 18 & 12 & 12 & 8 & 77 & 84 \\
\hline 2 & $\mathrm{MH}$ & MTK & 8 & 8 & 6 & 15 & 12 & 10 & 7 & 66 & 72 \\
\hline 3 & SYF & PKN & 9 & 8 & 6 & 18 & 12 & 10 & 7 & 70 & 76 \\
\hline 4 & NU & PKN & 10 & 10 & 8 & 16 & 11 & 10 & 8 & 73 & 79 \\
\hline 5 & $\mathrm{OK}$ & IPA & 10 & 10 & 8 & 18 & 12 & 10 & 8 & 76 & 83 \\
\hline 6 & SM & MTK & 9 & 10 & 6 & 16 & 9 & 9 & 6 & 65 & 71 \\
\hline 7 & NR & BI & 9 & 11 & 8 & 16 & 11 & 10 & 8 & 73 & 79 \\
\hline 8 & PR & BI & 9 & 10 & 8 & 18 & 12 & 10 & 8 & 75 & 82 \\
\hline 9 & RI & BING & 10 & 10 & 7 & 18 & 11 & 8 & 8 & 72 & 78 \\
\hline 10 & ET & IPS & 10 & 8 & 7 & 18 & 11 & 11 & 8 & 73 & 79 \\
\hline 11 & $\mathrm{NH}$ & IPS & 9 & 10 & 7 & 16 & 11 & 10 & 7 & 70 & 76 \\
\hline 12 & $\mathrm{NE}$ & PKN & 10 & 10 & 7 & 18 & 12 & 11 & 8 & 76 & 83 \\
\hline 13 & $\mathrm{JM}$ & IPA & 8 & 8 & 6 & 15 & 12 & 9 & 7 & 65 & 71 \\
\hline 14 & $\mathrm{ZU}$ & BING & 10 & 10 & 8 & 19 & 12 & 10 & 8 & 77 & 84 \\
\hline 15 & YS & AGM & 10 & 10 & 8 & 19 & 12 & 10 & 8 & 77 & 84 \\
\hline \multicolumn{3}{|c|}{ Jumlah } & 141 & 143 & 107 & 258 & 172 & 150 & 114 & \multicolumn{2}{|r|}{1085} \\
\hline \multicolumn{3}{|c|}{ Rata-rata } & 9 & 10 & 7 & 17 & 11 & 10 & 8 & \multicolumn{2}{|r|}{155} \\
\hline \multicolumn{3}{|c|}{ Persentase (\%) } & 78 & 83 & 70 & 77 & 79 & 83 & 80 & \multicolumn{2}{|c|}{$79 \%$} \\
\hline
\end{tabular}

Dilihat hasil supervisi akademik kopetensi pedagogik pada siklus I terdapat rata-rata skor dan hasil yang diperoleh setiap kompetensi pedagogik masing-masing memiliki pesentase sebagai berikut: (1) pada kompetensi I mengenal karakteristik peserta didik presentase guru skor sebesar $78 \%$ dari 15 guru; (2) pada kompetensi II menguasai teori belajar dan prinsip-prinsip pembelajaran guru skor sebesar $83 \%$ dari 15 guru ; (3) pada kompetensi III menguasai menguasai pengembanngan kurikulum guru skor sebesar $70 \%$ dari 15 guru; (4) pada kompetensi IV menguasai kegiatan yang mendidik guru skor sebesar $77 \%$ dari 15 guru; (5) pada kompetensi $\mathrm{V}$ guru memahami dan mengembangkan kurikulum guru skor sebesar 79\% dari 15 guru; (6) pada kompetensi VI guru melaksanakan komunikasi dengan peserta didik guru skor sebesar $83 \%$ dari 15 guru; (7) pada kompetensi VII guru melaksanakan penilaian dan evaluasi guru skor sebesar $80 \%$ dari 15 guru. Sehingga diketahui ada empat kompetensi yang perlu di tingkatkan dari setiap guru terutama pada kompetensi I, III, IV dan V karena masih dibawah rata -rata $80 \%$ yang diarapakan oleh sekolah berdasarkan kegiatan semester ganjil Tahun Pelajaran 2019/2020.

Pada siklus I, hasil observasi penelitian diperoleh gambaran bahwa presentase skor pada siklus I skor terendah $70 \%$ artinya bahwa tingkat pelaksanaan proses pembelajaran baik, tetapi masih ada beberapa guru yang harus dibina untuk memaksimalkan pemahaman tujuh kompetensi yang harus dikuasai oleh setiap guru. Terutama pada kompetensi pedagogik guru yang belum mencapai nilai maksimal. Berdasarkan tabel 1 dapat dilihat presentase tertinggi $83 \%$ artinya berada pada interpretasi baik sekali

Tabel 2. Rekapitulasi Hasil Nilai Rata-Rata Guru Kompetensi Pedagogik Siklus I

\begin{tabular}{|c|c|c|c|c|c|c|c|c|c|c|c|}
\hline \multirow{2}{*}{ No } & \multirow{2}{*}{$\begin{array}{l}\text { Kode } \\
\text { Guru }\end{array}$} & \multirow{2}{*}{ Mapel } & \multicolumn{7}{|c|}{ Rata- Rata Hasil Penilaian Kompetensi Pedagogik } & \multirow{2}{*}{$\begin{array}{c}\text { jumla } \\
\text { h }\end{array}$} & \multirow{2}{*}{$\begin{array}{l}\text { Rata- } \\
\text { rata }\end{array}$} \\
\hline & & & 1 & 2 & 3 & 4 & 5 & 6 & 7 & & \\
\hline 1 & $\mathrm{DB}$ & MTK & 83 & 83 & 70 & 82 & 86 & 100 & 80 & 584 & 83 \\
\hline 2 & $\mathrm{MH}$ & MTK & 67 & 67 & 60 & 68 & 86 & 83 & 70 & 501 & 72 \\
\hline 3 & SYF & PKN & 75 & 67 & 60 & 82 & 86 & 83 & 70 & 523 & 75 \\
\hline 4 & $\mathrm{NU}$ & PKN & 83 & 83 & 80 & 73 & 79 & 83 & 80 & 561 & 80 \\
\hline 5 & $\mathrm{OK}$ & IPA & 83 & 83 & 80 & 82 & 86 & 83 & 80 & 577 & 82 \\
\hline 6 & SM & MTK & 75 & 83 & 60 & 73 & 64 & 75 & 60 & 490 & 70 \\
\hline 7 & NR & BI & 75 & 92 & 80 & 73 & 79 & 83 & 80 & 562 & 80 \\
\hline 8 & PR & BI & 75 & 83 & 80 & 82 & 86 & 83 & 80 & 569 & 81 \\
\hline 9 & RI & BING & 83 & 83 & 70 & 82 & 79 & 67 & 80 & 544 & 78 \\
\hline 10 & ET & IPS & 83 & 67 & 70 & 82 & 79 & 92 & 80 & 553 & 79 \\
\hline 11 & $\mathrm{NH}$ & IPS & 75 & 83 & 70 & 73 & 79 & 83 & 70 & 533 & 76 \\
\hline 12 & $\mathrm{NE}$ & PKN & 83 & 83 & 70 & 82 & 86 & 92 & 80 & 576 & 82 \\
\hline 13 & JM & IPA & 67 & 67 & 60 & 68 & 86 & 75 & 70 & 493 & 70 \\
\hline 14 & ZU & BING & 83 & 83 & 80 & 86 & 86 & 83 & 80 & 581 & 83 \\
\hline 15 & YS & AGM & 83 & 83 & 80 & 86 & 86 & 83 & 80 & 581 & 83 \\
\hline \multicolumn{3}{|c|}{ Jumlah } & 1173 & 1190 & 1070 & 1174 & 1233 & 1248 & 1140 & & \\
\hline \multicolumn{3}{|c|}{ Rata-rata } & 78 & 79 & 71 & 78 & 82 & 83 & 76 & & \\
\hline \multicolumn{3}{|c|}{ Persentase (\%) } & 78 & 79 & 71 & 78 & 82 & 83 & 76 & & \\
\hline
\end{tabular}

Hasil supervisi akademik kompetensi pedagogik pada siklus I terdapat rata-rata hasil penilaian kompetensi pedagogik setiap guru dan diperoleh gambaran hasil penilaian sebagai berikut: diperoleh nilai tertinggi sebesar 83 dan terdapat tujuh orang guru dengan nilai dibawah rata-rata 80 yang diharapkan sekolah dari kegiatan semester ganjil yaitu 72, 75, 70, 78, 79, 76, dan 70 (table 2). 
Melihat hasil kekurangan siklus I masih ada beberapa guru yang harus di perbaiki yaitu pada kompetensi pedagogik dimana masih ada tujuh guru yang belum menguasai indikator secara keseluruhannya maka perlu adanya tindakan di antaranya :

Tabel 3. Jumlah Guru yang Perlu Ditingkatakan Kompetensi Pedagogik

\begin{tabular}{llc}
\hline No & Mata Pelajaran & Jumlah \\
\hline 1 & Matematika & 2 \\
\hline 2 & PKn & 1 \\
\hline 3 & Bahasa Inggris & 1 \\
\hline 4 & IPA & 1 \\
\hline 5 & IPS $\quad$ Total & 2 \\
\hline &
\end{tabular}

Diharapkan pada pelaksanaan selanjutnya kegiatan supervisi akademik pada kompetensi pedagogik guru dapat meningkat terutama pada kompetensi yang belum mencapai maksimal secara klasikal maupun secara individu yang masingmasing kompetensi terdiri dari beberapa indikator .

\section{Siklus 2}

Berdasarkan hasil penelitian pada siklus 1, maka masih terdapat aspek yang pelu ditingkatkan. Sehingga dilakukan upaya peningkatan kompetensi pedagogik guru SMP Negeri 4 Pontianak pada siklus 2. Berikut ini adalah data hasil observasi kompetensi pedagogik guru SMP Negeri 4 Pontianak pada siklus (Tabel 4 dan Tabel 5)

Tabel 4. Rekapitulasi Perolehan Skor Setiap Kompetensi Pedagogik Siklus 2

\begin{tabular}{|c|c|c|c|c|c|c|c|c|c|c|c|}
\hline \multirow[t]{2}{*}{ No } & \multirow{2}{*}{$\begin{array}{c}\text { Nama } \\
\text { Guru } \\
\text { (kode) }\end{array}$} & \multirow[t]{2}{*}{ Mapel } & \multicolumn{7}{|c|}{$\begin{array}{l}\text { Rata- Rata Perolehan Skor } \\
\text { Kompetensi Pedagogik }\end{array}$} & \multirow[t]{2}{*}{ Jumlah } & \multirow{2}{*}{$\begin{array}{c}\text { Persentase } \\
(100 \%)\end{array}$} \\
\hline & & & 1 & 2 & 3 & 4 & 5 & 6 & 7 & & \\
\hline 1 & DB & MTK & 11 & 10 & 8 & 18 & 13 & 12 & 9 & 81 & 88 \\
\hline 2 & MH & MTK & 9 & 9 & 7 & 17 & 12 & 10 & 8 & 72 & 78 \\
\hline 3 & SYF & \begin{tabular}{|l|} 
PKN \\
\end{tabular} & 10 & 9 & 7 & 18 & 12 & 10 & 8 & 74 & 80 \\
\hline 4 & NU & PKN & 11 & 11 & 9 & 18 & 11 & 10 & 9 & 79 & 86 \\
\hline 5 & OK & IPA & 11 & 10 & 8 & 18 & 12 & 11 & 9 & 79 & 86 \\
\hline 6 & SM & MTK & 9 & 10 & 6 & 16 & 10 & 9 & 7 & 67 & 73 \\
\hline 7 & NR & BI & 10 & 11 & 9 & 16 & 11 & 10 & 9 & 76 & 83 \\
\hline 8 & PR & BI & 10 & 10 & 9 & 19 & 13 & 10 & 9 & 80 & 87 \\
\hline 9 & RI & BING & 11 & 10 & 8 & 18 & 13 & 12 & 9 & 81 & 88 \\
\hline 10 & ET & IPS & 11 & 10 & 8 & 18 & 13 & 12 & 9 & 81 & 88 \\
\hline 11 & $\mathrm{NH}$ & IPS & 10 & 11 & 9 & 16 & 11 & 10 & 9 & 76 & 83 \\
\hline 12 & $\mathrm{NE}$ & PKN & 11 & 10 & 8 & 18 & 13 & 12 & 9 & 81 & 88 \\
\hline 13 & $\mathrm{JM}$ & IPA & 8 & 8 & 7 & 16 & 12 & 10 & 7 & 68 & 74 \\
\hline 14 & ZU & BING & 11 & 11 & 9 & 19 & 12 & 10 & 9 & 81 & 88 \\
\hline 15 & YS & AGM & 11 & 11 & 9 & 19 & 12 & 10 & 9 & 81 & 88 \\
\hline \multicolumn{3}{|c|}{ Jumlah } & 154 & 151 & 121 & 264 & 180 & 158 & 129 & \multicolumn{2}{|r|}{1157} \\
\hline \multicolumn{3}{|c|}{ Rata-rata } & 10 & 10 & 8 & 18 & 12 & 11 & 9 & \multirow{2}{*}{\multicolumn{2}{|c|}{$85 \%$}} \\
\hline \multicolumn{3}{|c|}{ Persentase (\%) } & 83 & 83 & 80 & 82 & 86 & 92 & 90 & & \\
\hline
\end{tabular}

Hasil supervisi akademik kompetensi pedagogik pada siklus II terdapat rata-rata hasil skor yang diperoleh setiap kompetensi pedagogik masing-masing memiliki pesentase sebagai berikut: (1) pada kompetensi I mengenal karakteristik peserta didik presentase guru skor sebesar $83 \%$ dari 15 guru; (2) pada kompetensi II menguasai teori belajar dan prinsip-prinsippembelajaran guru skor sebesar $83 \%$ dari 15 guru ; (3) pada kompetensi III menguasai menguasai pengembanngan kurikulum guru skor sebesar $80 \%$ dari 15 guru; (4) pada kompetensi IV menguasai kegiatan yang mendidik guru skor sebesar $82 \%$ dari 15 guru; (5) pada kompetensi $\mathrm{V}$ guru memahami dan mengembangkan kurikulum guru skor sebesar $86 \%$ dari 15 guru; (6) pada kompetensi VI guru melaksanakan komunikasi dengan peserta didik guru skor sebesar 92\% dari 15 guru; (7) pada kompetensi VII guru melaksanakan penilaian dan evaluasi guru skor sebesar $90 \%$ dari 15 guru, sehingga diketahui ada satu kompetensi yang perlu di tingkatkan dari setiap guru yaitu pada kompetensi III karena masih standar rata -rata $80 \%$ yang diarapakan oleh sekolah berdasarkan kegiatan semester ganjil Tahun Pelajaran 2019/2020. Pada siklus I, hasil observasi penelitian diperoleh gambaran bahwa presentase skor pada siklus I skor terendah $80 \%$ artinya bahwa tingkat pelaksanaan proses pembelajaran baik sekali dan presentase tertinggi $92 \%$ artinya berada pada interpretasi baik sekali (table 4).

Tabel 5. Rekapitulasi Hasil Nilai Rata-Rata Guru Kompetensi Pedagogik Siklus 2

\begin{tabular}{|c|c|c|c|c|c|c|c|c|c|c|c|}
\hline \multirow{2}{*}{ No } & \multirow{2}{*}{$\begin{array}{l}\text { Kode } \\
\text { Guru }\end{array}$} & \multirow{2}{*}{ Mapel } & \multicolumn{7}{|c|}{ Rata- Rata Hasil Penilaian Kompetensi Pedagogik } & \multirow{2}{*}{ Jumlah } & \multirow{2}{*}{$\begin{array}{l}\text { Rata- } \\
\text { rata }\end{array}$} \\
\hline & & & 1 & 2 & 3 & 4 & 5 & 6 & 7 & & \\
\hline 1 & DB & MTK & 97 & 83 & 80 & 82 & 93 & 100 & 90 & 625 & 89 \\
\hline 2 & MH & MTK & 75 & 75 & 70 & 77 & 86 & 83 & 80 & 546 & 78 \\
\hline 3 & SYF & PKN & 83 & 75 & 70 & 82 & 86 & 83 & 80 & 559 & 80 \\
\hline 4 & $\mathrm{NU}$ & PKN & 92 & 92 & 90 & 82 & 79 & 83 & 90 & 608 & 87 \\
\hline 5 & OK & IPA & 92 & 83 & 80 & 82 & 86 & 92 & 90 & 605 & 86 \\
\hline 6 & SM & MTK & 75 & 83 & 60 & 73 & 71 & 75 & 70 & 507 & 72 \\
\hline 7 & NR & BI & 83 & 92 & 90 & 73 & 79 & 83 & 90 & 590 & 84 \\
\hline 8 & PR & $\mathrm{BI}$ & 83 & 83 & 90 & 86 & 93 & 83 & 90 & 608 & 87 \\
\hline 9 & RI & BING & 92 & 83 & 80 & 82 & 93 & 100 & 90 & 620 & 89 \\
\hline 10 & ET & IPS & 92 & 83 & 80 & 82 & 93 & 100 & 90 & 620 & 89 \\
\hline 11 & $\mathrm{NH}$ & IPS & 83 & 92 & 90 & 73 & 79 & 83 & 90 & 590 & 84 \\
\hline 12 & $\mathrm{NE}$ & PKN & 92 & 83 & 80 & 82 & 93 & 100 & 90 & 620 & 89 \\
\hline 13 & $\mathrm{JM}$ & IPA & 67 & 67 & 70 & 73 & 86 & 83 & 70 & 516 & 74 \\
\hline 14 & ZU & BING & 92 & 92 & 90 & 86 & 86 & 83 & 90 & 619 & 88 \\
\hline 15 & YS & AGM & 92 & 92 & 90 & 86 & 86 & 83 & 90 & 619 & 88 \\
\hline \multicolumn{3}{|c|}{ Jumlah } & 1290 & 1258 & 1210 & 1201 & 1289 & 1314 & 1290 & & \\
\hline \multicolumn{3}{|c|}{ Rata-rata } & 86 & 84 & 81 & 80 & 86 & 88 & 86 & & \\
\hline \multicolumn{3}{|c|}{ Persentase (\%) } & 86 & 84 & 81 & 80 & 86 & 88 & 86 & & \\
\hline
\end{tabular}

Hasil supervisi akademik kompetensi pedagogik pada siklus II terdapat rata-rata hasil penilaian kompetensi pedagogik setiap guru dan diperoleh gambaran hasil penilaian sebagai berikut: 
diperoleh nilai tertinggi sebesar 89 dan masih terdapat tiga orang guru dengan nilai dibawah ratarata 80 yang diharapkan sekolah dari kegiatan semester ganjil yaitu 78, 72, dan 74 (table 5).

\section{Pembahasan}

Berdasarkan analisis hasil siklus I dan II, kompetensi guru secara umum dalam pelaksanaan supervisi akademik pada proses pembelajaran mengalami peningkatan persentase pada tiap kompetensi, pada siklus I hasil terendah mencapai rata-rata $70 \%$ ( baik) dan pada siklus II nilai terendah mencapai rata-rata $80 \%$ (baik),sedangkan pada siklus I hasil tertinggi mencapai rata-rata $83 \%$ ( baik) dan pada siklus II mencapai rata-rata 92\% (baik sekali). Terdapat peningkatan kemampuan guru sebesar 6\% dari siklus I dibandingakan siklus II. Adapun ketercapaian kemampuan pada setiap indikator dan besarnya persentase pencapaian kemampuan pada setiap aspek dapat dilihat pada table 6 berikut ini.

Berdasarkan table 6, masih terlihat aspek-aspek yang membutuhkan perbaikan pada masa yang akan datang. Berikut ini akan dikomparasikan sejumlah keadaan awal dengan kondisi akhir pada siklus II pada table 46

Tabel 6. Rekapitulasi Rata-Rata Hasil Kompetensi Pedagogik

\begin{tabular}{|c|c|c|c|c|}
\hline No & $\begin{array}{c}\text { Vraian Kompetensi } \\
\text { Pedagogik }\end{array}$ & $\begin{array}{c}\text { (Sikdus I) } \\
\text { (\%) }\end{array}$ & $\begin{array}{c}\text { (Siaclas II) } \\
(\%)\end{array}$ & $\begin{array}{c}\text { Peniagkatan } \\
\text { (\%) }\end{array}$ \\
\hline 1. & $\begin{array}{l}\text { Mengenal karakteristik } \\
\text { peserta didik }\end{array}$ & 78 & 83 & 5 \\
\hline 2. & $\begin{array}{l}\text { Menguasai teori belajar } \\
\text { dan prinsip-prinsip } \\
\text { pembelajaran }\end{array}$ & 83 & 87 & 0 \\
\hline 3. & $\begin{array}{l}\text { Pengembangan } \\
\text { kurikulum }\end{array}$ & 70 & 80 & 10 \\
\hline 4. & $\begin{array}{l}\text { Kegiatan pembelajaran } \\
\text { yang mendidik }\end{array}$ & 77 & 82 & 5 \\
\hline 5. & $\begin{array}{l}\text { Memabami dan } \\
\text { mengembanglcan } \\
\text { potensi }\end{array}$ & 79 & 86 & 7 \\
\hline 6. & $\begin{array}{l}\text { Komunikasi dengan } \\
\text { peserta dadik }\end{array}$ & 83 & 92 & 9 \\
\hline 7. & Penilaian dan evaluasi & 80 & 90 & 10 \\
\hline
\end{tabular}

Berdasarkan tabel 6 Rata-rata hasil kompetensi siklus II meningkat dibandingkan siklus I, ini membuktikan terjadi peningkatan terjadi peningkatan kompetensi guru.pada masing -masing kompetensi. Pada siklus II terdapat rata-rata hasil penilaian kompetensi pedagogik setiap kompetensi masing-masing memiliki pesentase sebagai berikut: (1) pada kompetensi I mengenal karakteristik peserta didik meningkat sebesar 5\% dari siklus I;
(2) pada kompetensi II menguasai teori rinsipprinsippembelajaran meningkat sebesar $0 \%$ dari siklus I; (3) pada kompetensi III menguasai menguasai pengembanngan kurikulum meningkat sebesar $10 \%$ dari siklus I; (4) pada kompetensi IV menguasai kegiatan yang mendidik guru meningkat sebesar 5\% dari siklus I; (5) pada kompetensi $\mathrm{V}$ guru memahami dan mengembangkan kurikulum meningkat sebesar 7\% dari siklus I; (6) pada kompetensi VI guru melaksanakan komunikasi dengan peserta didik meningkat sebesar 9\% dari siklus I; (7) pada kompetensi VII guru melaksanakan penilaian dan evaluasi meningkat sebesar $10 \%$ dari siklus I, kompetensi yang dicapai guru baik rata -rata kompetensi terendah sudah mencapai hasil 80\% pada siklus II dibandingkan siklus I hasil terendah $70 \%$ ini menunjukan adanya peningkatan kopetensi pedagogik guru pada kegiatan siklus II sebesar 10\% dibandingkan siklus I, semester ganjil Tahun Pelajaran 2019/2020.

\section{SIMPULAN DAN SARAN}

\section{Simpulan}

Berdasarkan hasil analisis data dari penelitian yang telah dilakukan, maka dapat disimpulkan bahwa: (1)Perencanaan supervisi akademik untuk meningkatkan kompetensi pedagogik guru direncanakan sebanyak 2 kali pengamatan dalam 2 siklus dengan 15 orang guru yang diamati; (2)Pelaksanaan supervisi akademik untuk meningkatkan kompetensi pedagogik guru dilakukan dalam 2 siklus, siklus pertama dilaksanakan pada bulan september dan siklus kedua dilaksanakan pada bulan oktober. Penilaian dilakukan dengan mengisi intrumen penilaian kompetensi pedagogik guru melalui supervisi; dan (3)Hasil supervisi akademik untuk meningkatkan kompetensi pedagogik guru melalui supervisi dan refleksi tergambarkan oleh hasil pengamatan selama 2 siklus, kompetensi pedagogik guru dalam pelaksanaan proses pembelajaran mengalami peningkatan melalui supervisi akademik pada siklus II. Pada siklus I nilai terendah sebesar $70 \%$ dan pada siklus II nilai terendah sebesar $80 \%$. Rata-rata nilai tertinggi pada siklus I adalah $79 \%$ dan rata-rata nilai tertinggi pada siklus 2 sebesar $84 \%$. terdapat peningkatan presentase kompetensi guru sebesar 5\% dari siklus I. Terjadi peningkatan rata-rata kompetensi pedagogik guru dalam 
mengenal karakteristik peserta didik sebesar $8 \%$, kompetensi guru dalam pengembangan kurikulum meningkat sebesar $11 \%$, kompetensi guru dalam kegiatan pembelajaran yang mendidik meningkat sebesar 3\% dan kompetensi guru dalam memahami dan mengembangkan potensi meningkat sebesar $7 \%$.

\section{Saran}

Berdasarkan kesimpulan dan hasil dari penelitian yang telah dilakukan, beberapa saran yang peneliti dapat sampaikan antara lain: (1) Kepala Sekolah hendaknya meningkatkan kemapuan untuk membina, agar guru yang ada di SMP N 4 Pontianak lebih mamahami tugasnya secara profesional; (2) guru hendaknya meningkatkan kemampuan kompetensi pedagogik dalam melaksanakan tugas sebagai pendidik.

\section{DAFTAR RUJUKAN}

Arikunto, Suharsimi. 2009. Dasar-dasar Evaluasi Pendidikan. Jakarta: Bumi Aksara

Peraturan Pemerintah Nomor 14. 2007. Tentang Guru. Jakarta: Depdiknas

Purwanto, M. Ngalim. 1987. Prinsip-prinsip dan Teknik Evaluasi Pengajaran. Bandung: Remaja Rosdakarya

Kusnandar. 2008. Langkah mudah penelitian Tindakan kelas segai pengembang Profesi Guru. Jakarta: Rajawali Pers. 